\title{
Sedimentation Processes: Geomorphological evidence for staged sand dam construction
}

\author{
Jonathan Viducich ${ }^{1}$ and John Selker ${ }^{1}$ \\ ${ }^{1}$ Oregon State University
}

February 5, 2021

\begin{abstract}
Steam sediment transport is a convolution of climate, weather, geology, topography, biology, and human influence. In addition to providing water and food security for dryland rural communities, sand dams - small weirs designed to trap only the coarse fractions of transported sediments in seasonal and ephemeral streams-illuminate many complexities of geomorphological dynamics. Sand dams store water in interstitial riverbed pores and the size of deposited sediment particles largely determines the recoverability of stored water: fine materials limit transmission and provide lower volumetric yield. Can a sand dam be designed for a particular reach-scale, hydro-sedimentary context to limit capture of fine particles? We argue that the Rouse number provides a useful criterion for identifying regimes where the target material grades are trapped. These ideas were tested using sediment data collected in Kenya and HEC-RAS numerical simulations to evaluate the sensitivity of sedimentation processes to spillway height. We show that constructing sand dams in stages results in more targeted trapping of coarse material. Surprisingly, sedimentation is shown to be more sensitive to variation in spillway height than the flood hydrograph, especially when a dam is short. A method for evaluating the need for spillway staging (essentially controlling the bedform) based on the modeled Rouse number allows evaluation of costs and expected benefits. Beyond sand dams, this supports the observation that for dryland streams with peaky flows and high sediment loading, local hydraulic controls are typically more diagnostic of streambed sediment composition than is the sediment source.
\end{abstract}

1. Title: Sedimentation Processes: Geomorphological evidence for staged sand dam construction

2. Short running title: Evidence for staged sand dam construction

3. Authors: Jonathan M.G. Viducich11Lifewater International, P.O. Box 3131 San Luis Obispo, CA 93403, USA; John S. Selker

4. Institutional affiliations: Biological and Ecological Engineering Department, Oregon State University, Corvallis, OR, USA

5. Acknowledgements:The authors wish to thank Betty Miner, the Evans family and Oregon State University's Humanitarian Engineering program for their generous financial support, without which this research would not have been possible. Also, special thanks to Sahelian Solutions, the African Sand Dam Foundation, and Erik Nissen-Petersen of ASAL Consultants for their invaluable logistical support and generous hospitality, along with their commitment to water security for Kenya's dryland communities.

\section{Hosted file}

Sand Dams for HP_Viducich_Selker.pdf available at https://authorea.com/users/393970/ articles/507457-sedimentation-processes-geomorphological-evidence-for-staged-sand-damconstruction 

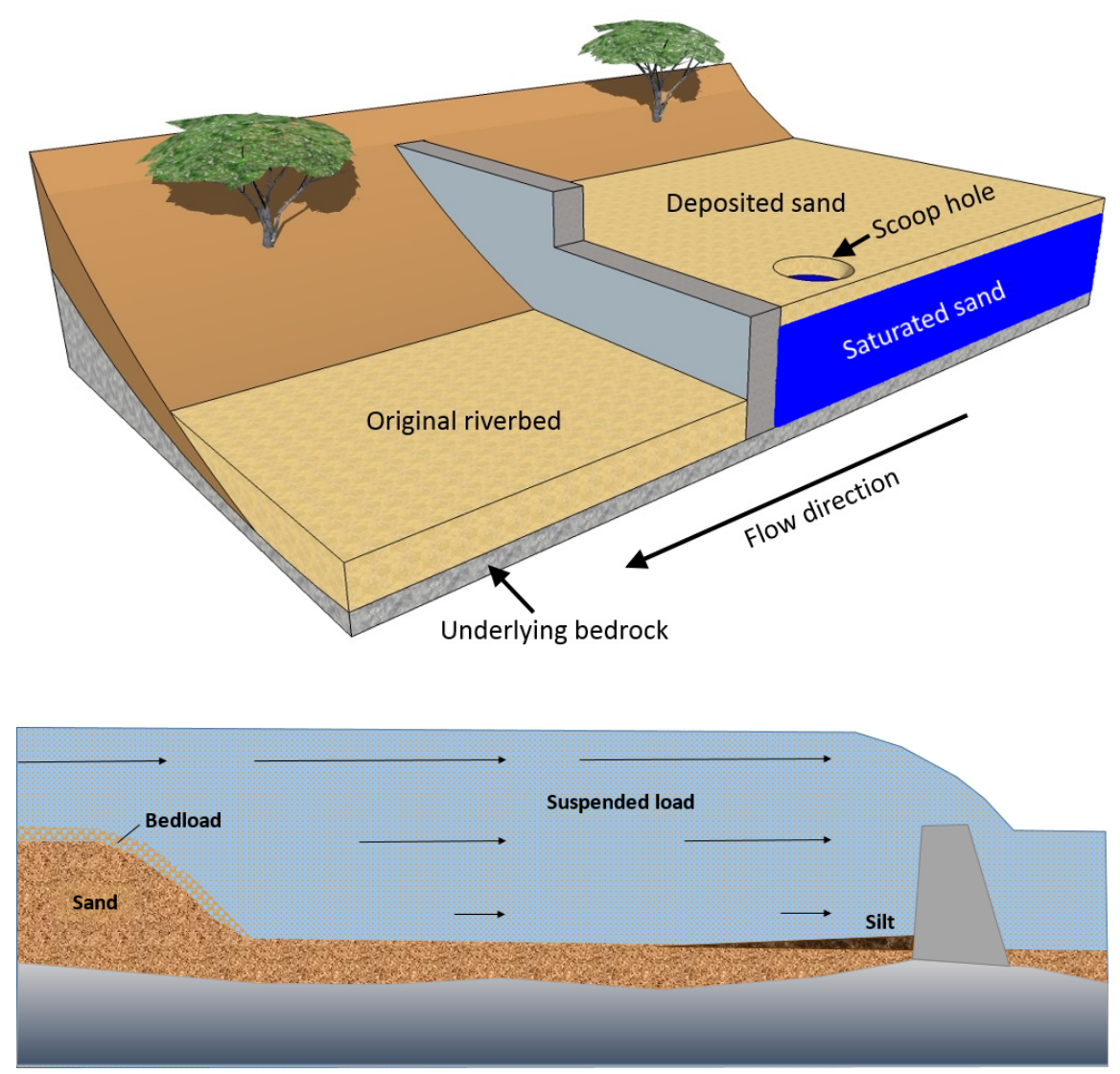
$\|$ 

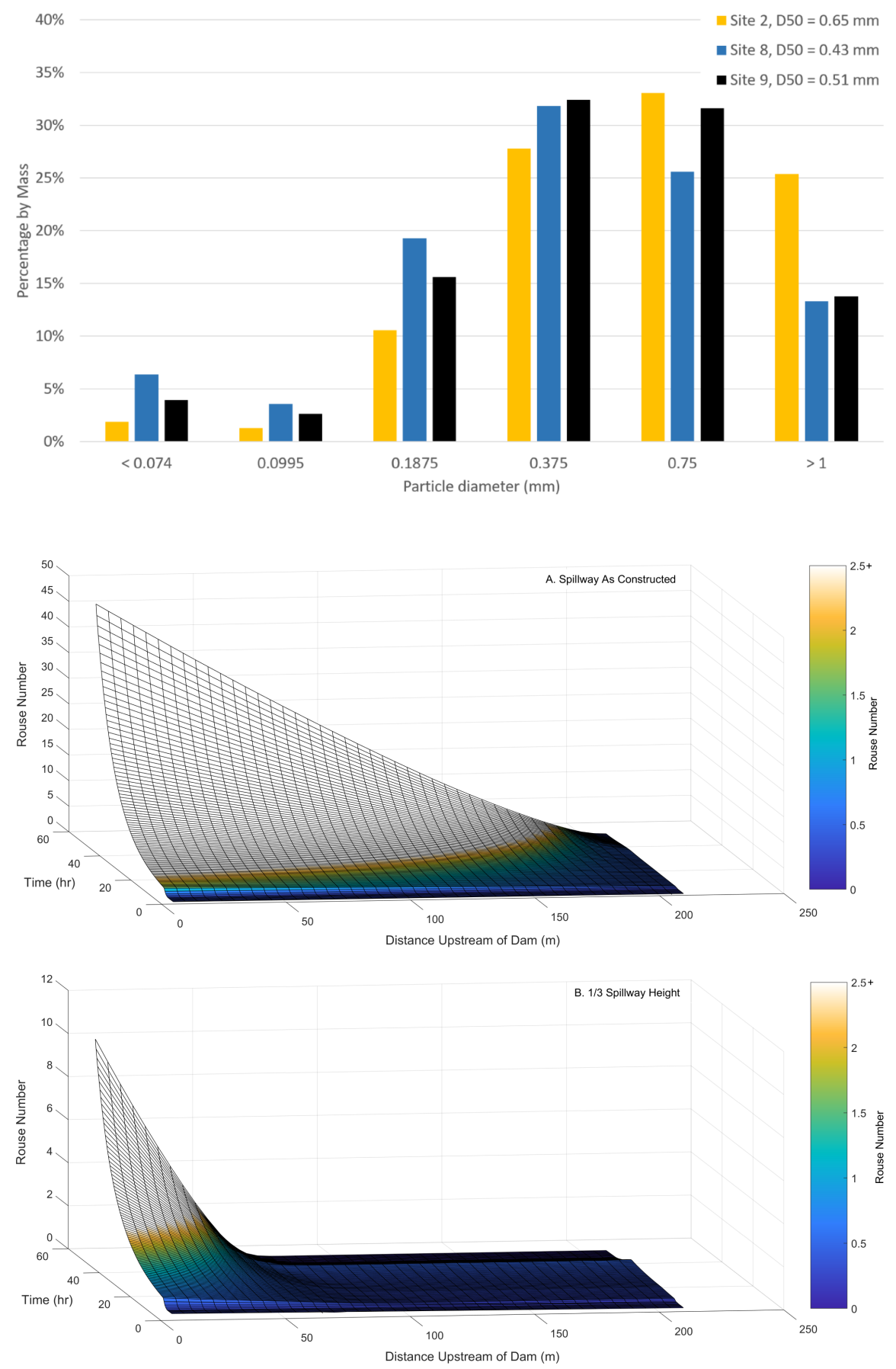